\title{
Electroacoustic and electrophysiological auditory assessment in aphasic individuals
}

\author{
Ana Karina Lima Buriti ${ }^{1}$ \\ https://orcid.org/0000-0001-9504-9795 \\ Lilian Aguiar de Mello ${ }^{1}$ \\ https://orcid.org/0000-0002-7086-802X
}

Bruna de Souza Pedroso Machado' https://orcid.org/0000-0003-0377-1487

Daniela Gil ${ }^{1}$

https://orcid.org/0000-0002-8647-6813
Universidade Federal de São Paulo - UNIFESP, Departamento de Fonoaudiologia, São Paulo, São Paulo, Brasil.

Paper developed at the Speech-LanguageHearing Department of the Universidade Federal de São Paulo - UNIFESP, São Paulo, São Paulo, Brazil.

Conflict of interests: Nonexistent

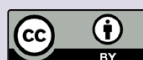

Received on: November 2, 2019 Accepted on: March 27, 2020

Corresponding address: Ana Karina Lima Buriti

Rua Botucatu, 802, Vila Clementino CEP: 04023-062 - São Paulo, São Paulo, Brasil

E-mail: anak_buriti@yahoo.com.br

\section{ABSTRACT}

Purpose: to verify the functioning of the outer hair cells and the medial efferent olivocochlear system, and the integrity of the auditory pathways in the brainstem up to the auditory cortex, in aphasic individuals.

Methods: the sample comprised 20 individuals - 10 without aphasia and 10 with it, aged from 21 to 58 years. The procedures used were the research of the otoacoustic emissions by a transient stimulus with and without noise, and the cognitive potential (tone-burst and speech stimuli). The findings were analyzed based on descriptive statistics.

Results: the suppression effect was more present in individuals without aphasia when compared with the aphasic ones. In the cognitive potential, the mean latency values of P3 was within normality standards, with a higher latency in the individuals presented with aphasia for the tone-burst stimulus in both ears. A statistically significant difference of the P3-N2 amplitude was observed for the tone-burst stimulus, comparing the ears in both groups, and for speech stimulus only to the left ear in both groups.

Conclusions: aphasic individuals did not present significant differences regarding suppression of the otoacoustic emissions. As for the cognitive potential, the aphasic individuals presented higher latency values when compared to those with no aphasia.

Keywords: Aphasia; Hearing; Auditory Evoked Potentials; Auditory Hair Cells 


\section{INTRODUCTION}

Aphasia is a disturbance in the content, form and use of language, as well as in its underlying cognitive processes, such as perception and memory ${ }^{1}$. It is caused by an organic brain injury, usually on the left hemisphere, resulting from a series of triggering factors. The most common etiologies are stroke, metabolic diseases, aneurysms, head injuries, degenerative and demyelinating diseases, among others ${ }^{2}$.

The audiological assessment of an aphasic person requires greater attention from the examiner, as it can be difficult to obtain consistent answers due to the neurological sequela and the existence of associated motor impairments that can alter communication in general. Hence, the need for objective procedures is noted, since the disturbance in communication can hinder data interpretation in an audiological assessment ${ }^{3}$.

Individuals with the integrity of the auditory pathways present reduced amplitude of transient evoked otoacoustic emissions (TEOAE) responses when noise is presented simultaneously with the click stimulus - a phenomenon known as suppression. The suppression effect is verified by comparing the general response values in each ear in both the presence and absence of suppressor noise ${ }^{4,5}$.

Despite the shortage of studies investigating the suppression effect of otoacoustic emissions in aphasics, one ${ }^{6}$ stands out which did not verify any statistically significant difference between right and left ears, neither any advantage of the right ear for the general response values of the otoacoustic emissions with and without contralateral noise in a population of individuals with normal hearing and no neurological alterations.

In another study ${ }^{7}$, only the transient otoacoustic emissions were investigated in aphasic individuals, in which $44.2 \%$ of them presented the absence of TEOAE in one or more frequencies, either early detecting alteration in the cochlea or confirming the already existing alteration.

Researchers have been investigating the cognitive potential in aphasics. A study ${ }^{8}$ noted the absence of cognitive potential response in seven aphasic individuals (58.3\%), with higher latency and amplitude values observed when the stimulation was conducted in the left ear. The findings confirmed that a brain injury can change both the peripheral and central auditory pathway structures.

Another study ${ }^{9}$ also with the cognitive potential in aphasics revealed six individuals (64.7\%) with the absence of the N2 and P3 waves. The other ones presented increased latency and reduced amplitude, which can be related to the fatigability aphasic individuals tend to present in situations requiring attention, as well as to the presence of injuries in language-related areas resulting from a stroke in the left hemisphere.

Thus, this study aimed to verify the functioning of the outer hair cells and the medial efferent olivocochlear system, as well as the integrity of the auditory pathways in the brainstem up to the auditory cortex, in aphasic individuals.

\section{METHODS}

This is a cross-sectional, observational study conducted in the audiology and electrophysiology outpatient clinic of the Universidade Federal de São Paulo - UNIFESP, SP, Brazil, approved by the Research Ethics Committee of that institution, under protocols no. 385661 and no. 820216 . The individuals selected signed the Informed Consent Form (ICF) in compliance with Resolution no. 466/2012.

A total of 20 individuals were assessed, aged from 21 to 58 years, divided into two groups: study group (SG), comprising 10 individuals with aphasia, and control group (CG), comprising 10 individuals without neurological injury. The groups were matched for age and gender, with seven females and three males.

The aphasic individuals were selected from a list of patients being treated at the Acquired Neurological Disorders outpatient center of the speech-languagehearing department of the Universidade Federal de São Paulo, who met the inclusion criterion of being diagnosed with aphasia. The inclusion criteria used for both groups ( $S G$ and $C G$ ) were as follows: the absence of psychiatric and neurological alterations, type $A$ tympanometric curve $^{10}$, auditory thresholds within limits of normality' ${ }^{11}(\leq 25 \mathrm{~dB} \mathrm{HL}$ ) in $250 \mathrm{~Hz}$ to $4000 \mathrm{~Hz}$ frequencies bilaterally, and integrity of auditory pathway until the brainstem through the brainstem auditory evoked potentials (BAEP) neurological protocol ${ }^{12}$.

The electroacoustic assessment was composed of the research of the transient otoacoustic emissions and the suppression effect. They were carried out in a sound booth, with probes calibrated at the beginning of the assessment, using the ILO V6 Otodynamics brand equipment, attached to a portable microcomputer.

The TEOAE were analyzed through the observation of the following aspects: general reproducibility over $70 \%$, probe stability over $70 \%$, and stimulus sound 
pressure level between 75 and $85 \mathrm{~dB}$ peSPL. The criterion considered for the presence of response was when it occurred at $3 \mathrm{~dB}$ above the noise in the 1-to-4-kHz frequency band ${ }^{13}$.

The otoacoustic emissions used to assess the presence of suppression effect was picked up in the presence of noise in the contralateral ear; the ear the test begun with was randomly chosen. The probes were placed in each of the person's external acoustic meatuses; in one of the probes, the linear click stimuli were presented at $65 \mathrm{~dB}$ peSPL, and in the other one, the broadband noise (white noise) at $60 \mathrm{dBpeSPL}{ }^{14}$. The stimulus was presented in alternated blocks, with 15 seconds of noiseless linear clicks and then 15 seconds of linear clicks with contralateral noise, totaling 260 registered stimuli per ear.

The OAE suppression was calculated by subtracting the response amplitude of the noiseless OAE from the response amplitude of the OAE with contralateral acoustic stimulation. The suppression effect was considered present when there was a reduction greater than $0.2 \mathrm{~dB}$ SPL in the general response (calculated by the equipment itself), as well as in the frequency bands ${ }^{14}$.

The electrophysiologic auditory assessment was conducted with the Smart EP equipment, manufactured by Intelligent Hearing Systems (IHS). The auditory evoked potentials were picked up in an electrically protected, acoustically treated room. The individuals were comfortably seated in a reclining chair and instructed to get as relaxed as possible, avoiding movements especially of head and neck musculature, to avoid myogenic artifacts. The patients' skin was cleaned with abrasive paste so that the electrodes could be fixed with electrolytic paste and adhesive tape, following Jasper's ${ }^{15}$ proposal and under the 10-20 system - i.e., an electrode on the vertex $(\mathrm{Cz})$, one in each earlobe (A1 left, and A2 right), and one on the forehead, considering the ground electrode (Fpz). The electrodes immittance was measured so it would be below $5 \mathrm{k} \Omega$ (Kiloohm) with a maximum inter-electrode difference of $2 \mathrm{k} \Omega$.

The acoustic stimuli were presented through the ER-3A insert earphone, fitted in the external acoustic meatus (EAM) with disposable foam plugs. The assessments were carried out in a single two-hour session.

To obtain the cognitive potential, the auditory stimulus was binaurally presented according to the rare/frequent oddball paradigm. Tone-burst stimuli were used $(1000 \mathrm{~Hz}$ frequency for the frequent stimulus, and $2000 \mathrm{~Hz}$ frequency for the rare stimulus), as well as complex stimuli (speech) (/da/ syllable for the frequent stimulus, and /ga/ syllable for the rare stimulus). A total of 300 stimuli was presented -240 for the frequent stimulus and 60 for the rare one, in a proportion of $80 \%$ for the frequent stimulus and $20 \%$ for the rare one. The intensity of the stimulus presentation was $70 \mathrm{~dB} \mathrm{HL}$, using alternating polarity, at the speed of 1.1 second, filter $1-30 \mathrm{~Hz}$, and window of $600 \mathrm{~ms}$.

The individuals were instructed to pay attention to the rare stimulus, counting how many times it appeared; this number was informed at the end of the test. Before beginning the signal pick-up, the individuals were trained for the task to ensure they understood the procedure and were familiar with the stimuli. Because of aphasia, some individuals were unable to count. In these cases, they were instructed to press as the examiner's hand every time they perceived the rare stimulus.

Two waves were registered, one for the frequent stimulus and another for the rare one. The amplitude and latency values were obtained through identifying the waves in the peak of greater amplitude; N2 and P3 were marked in the analyzed tracing, considering the subtraction of the frequent tracing from the rare one.

The latency and amplitude normality values of $\mathrm{P} 3$ were analyzed according to the age groups ${ }^{16}$.

Statistical analysis

For the data analysis, the following statistical tests were applied: Mann-Whitney test, to compare the results between groups. Wilcoxon test, to compare the stimuli in each group, because the data was matched - i.e., the same subject served as research and comparison of themselves.

\section{RESULTS}

The mean age of the individuals who participated in the research was 35.5 years. Females represented a little more than half of the subjects (56\%).

The OAE results with research of suppression effect in the individuals with and without aphasia are presented in Table 1, comparing them according to the side of the ear.

The amplitude response was reduced in the presence of noise. Only in the SG, there was a statistically significant difference verified between the ears in the OAE with and without noise (Table 1). 
Table 1. Comparison, between ears, of the amplitude of the otoacoustic emission in the research of suppression effect in individuals with and without aphasia

\begin{tabular}{cccccccccc}
\hline Exam & Ear & Mean & Median & SD & Q1 & Q3 & N & CI & P-value \\
\hline OAE (CG) & & & & & & & & & \\
Noiseless & RE & 10.2 & 9.7 & 6.6 & 4.9 & 14.2 & 10 & 4.1 & \\
& LE & 9.7 & 8.8 & 5.8 & 4.9 & 12.4 & 10 & 3.6 & $p=0.722$ \\
With noise & RE & 9.4 & 8.6 & 6.8 & 4.1 & 13.7 & 10 & 4.2 & \\
& LE & 9.2 & 8.0 & 5.6 & 5.1 & 11.8 & 10 & 3.5 & $p=0.683$ \\
Difference & RE & 0.82 & 0.60 & 0.73 & 0.40 & 0.88 & 10 & 0.46 & \\
& LE & 0.54 & 0.30 & 0.71 & 0.05 & 0.75 & 10 & 0.44 & $p=0.384$ \\
\hline OAE (SG) & & & & & & & & & \\
\hline Noiseless & RE & 11.9 & 10.1 & 5.4 & 7.7 & 16.0 & 10 & 3.3 & \\
& LE & 10.0 & 9.4 & 7.0 & 3.4 & 16.3 & 10 & 4.4 & $\mathrm{p}<0.035^{*}$ \\
With noise & RE & 11.1 & 8.9 & 5.7 & 6.8 & 15.4 & 10 & 3.6 & \\
& LE & 9.1 & 8.5 & 7.6 & 2.3 & 15.8 & 10 & 4.7 & $\mathrm{p}<0.050^{*}$ \\
Difference & RE & 0.85 & 0.55 & 0.98 & 0.30 & 0.98 & 10 & 0.61 & \\
& LE & 0.87 & 0.65 & 0.93 & 0.22 & 0.88 & 10 & 0.58 & $p=0.539$ \\
\hline
\end{tabular}

Legend: OAE - otoacoustic emissions, CG - control group, SG - study group, RE- right ear, LE- left ear, Q1 - first quartile (25\%), Q3 - third quartile (75\%), $\mathrm{n}$ - subjects, $\mathrm{Cl}$ - Confidence Interval. Statistical test: Wilcoxon.

The occurrence of suppression of otoacoustic emissions in the control and study groups was noted, as seen in Table 2. The presence of suppression was more prevalent in both groups $-70 \%$ in the CG, and $60 \%$ in the SG.

Table 2. The occurrence of suppression of otoacoustic emissions in the control group and study group $(n=20)$

\begin{tabular}{lcccc}
\hline Variables & \multicolumn{2}{c}{ Control Group } & \multicolumn{2}{c}{ Study Group } \\
\cline { 2 - 5 } & $\mathbf{n}$ & $\%$ & $\mathbf{n}$ & $\%$ \\
\hline Suppression OAE & & & 06 & 60 \\
Present & 07 & 70 & 04 & 40 \\
Absent & 03 & 30 & 10 & 100 \\
Total & 10 & 100 & & \\
\hline
\end{tabular}

Legend: OAE - otoacoustic emissions, $n$ - number of subjects.

It is important to highlight that, for long-latency auditory evoked potentials (Tables 3 and 4), the results obtained from 18 individuals - nine without aphasia (CG), and nine aphasics (SG) - were analyzed. Two individuals were excluded because one of them, from the SG, did not attend the LLAEP pick-up session, even after repeated calls; hence, this person's correspondent in the control group was also excluded for the number of subjects to remain balanced.

The results of the cognitive potentials with tone-burst and speech stimuli are verified in Table 3, represented by the latency values of N2 and P3 and P3 amplitude in the individuals with and without aphasia.

A statistically significant difference $(p<0.015$ and $p<0.058$ ) was observed in the P3 amplitude results for the tone-burst stimulus, comparing the groups for each ear. As for the speech stimulus, a statistically significant difference $(p<0.038)$ was noted only for the left ear when the groups were compared (Table 3). Another result that stood out was that P3 amplitude presented lower values for the SG in both right and left ears, for tone-burst as well as speech stimuli. 
Table 3. Descriptive measures of N2 and P3 latencies and P3-N2 amplitudes with tone-burst stimulus and speech stimulus in individuals with aphasia $(n=9)$ and without aphasia $(n=9)$, comparing between ears

\begin{tabular}{|c|c|c|c|c|c|c|}
\hline Variable & Ear & Group & Mean & Median & SD & P-value \\
\hline \multicolumn{7}{|c|}{ P300 with tone-burst stimulus } \\
\hline \multirow{4}{*}{ N2 latency } & \multirow{2}{*}{ RE } & CG & 235.7 & 242 & 40.7 & \multirow{2}{*}{$p=0.453$} \\
\hline & & SG & 221.9 & 226 & 40.1 & \\
\hline & \multirow{2}{*}{ LE } & CG & 242.7 & 259 & 39.4 & \multirow{2}{*}{$p=0.133$} \\
\hline & & SG & 220 & 230 & 38.9 & \\
\hline \multirow{4}{*}{ P3 latency } & \multirow{2}{*}{ RE } & CG & 313.6 & 311 & 25.8 & \multirow{2}{*}{$p=0.757$} \\
\hline & & SG & 318.1 & 313 & 40.7 & \\
\hline & \multirow{2}{*}{ LE } & CG & 312.7 & 308 & 22.2 & \multirow{2}{*}{$p=0.270$} \\
\hline & & SG & 331.9 & 318 & 36.2 & \\
\hline \multirow{4}{*}{ P3-N2 amplitude } & \multirow{2}{*}{$\mathrm{RE}$} & CG & 8.92 & 7.9 & 3.57 & \multirow{2}{*}{$p<0.015^{\star}$} \\
\hline & & SG & 4.48 & 4.55 & 2.71 & \\
\hline & \multirow{2}{*}{ LE } & CG & 8.26 & 7.65 & 3.43 & \multirow{2}{*}{$p<0.058^{*}$} \\
\hline & & SG & 5.1 & 3.07 & 4.03 & \\
\hline \multicolumn{7}{|c|}{ P300 with speech stimulus } \\
\hline \multirow{4}{*}{ N2 latency } & \multirow{2}{*}{ RE } & CG & 230.4 & 225 & 36 & \multirow{2}{*}{$p=0.596$} \\
\hline & & SG & 219.4 & 224 & 22.5 & \\
\hline & \multirow{2}{*}{ LE } & CG & 234.7 & 230 & 37.8 & \multirow{2}{*}{$p=0.200$} \\
\hline & & SG & 216.1 & 214 & 22.3 & \\
\hline \multirow{4}{*}{ P3 latency } & \multirow{2}{*}{$\mathrm{RE}$} & CG & 326.3 & 330 & 39.8 & \multirow{2}{*}{$p=0.210$} \\
\hline & & SG & 296.1 & 281 & 50.4 & \\
\hline & \multirow{2}{*}{ LE } & CG & 335.3 & 350 & 34.3 & \multirow{2}{*}{$p=0.289$} \\
\hline & & $S G$ & 306.7 & 278 & 51.8 & \\
\hline \multirow{4}{*}{ P3-N2 amplitude } & \multirow{2}{*}{$\mathrm{RE}$} & CG & 7.11 & 7.52 & 3.36 & \multirow{2}{*}{$p=0.070$} \\
\hline & & SG & 4.2 & 3.65 & 2.96 & \\
\hline & \multirow{2}{*}{ LE } & CG & 7.29 & 7.01 & 3.27 & \multirow{2}{*}{$p<0.038^{*}$} \\
\hline & & $S G$ & 4.4 & 3.69 & 2.57 & \\
\hline
\end{tabular}

Legend: $\mu \mathrm{V}=$ microvolts; $\mathrm{N} 2=\mathrm{N} 200 ; \mathrm{P} 3=\mathrm{P} 300 ; \mathrm{N}=$ sample size; $\mathrm{SD}=$ standard deviation; $\mathrm{RE}=$ right ear; $\mathrm{LE}=$ left ear; $\mathrm{CG}=$ control group; $\mathrm{SG}=$ study group. *significant values $(p<0.05)$. Statistical test: Wilcoxon.

The relationship between the potential eliciting stimuli for each ear and between the groups is presented in Table 4. No statistically significant difference was observed in any of the relationships. The mean value for cognitive potential latency (P300) was within normality standards, with higher latency in the study group for the tone-burst stimulus in both ears. As for the speech stimulus, the mean value for P300 latency was higher in the control group in both ears. There was no statistically significant difference in the comparison between the ears and between types of potential eliciting stimuli (Table 4).

It is important to highlight that the P3 mean amplitude values in the control group was from $40 \%$ to $50 \%$ higher for both tone-burst and speech stimuli when compared to the study group. 
Table 4. Descriptive measures of P3 latency and P3-N2 amplitudes with tone-burst stimulus and speech stimulus in individuals with aphasia $(n=9)$ and without aphasia $(n=9)$, comparing the types of eliciting stimuli

\begin{tabular}{|c|c|c|c|c|c|c|c|c|}
\hline \multirow{3}{*}{$\begin{array}{l}\text { Variable } \\
\text { Stimuli } \\
\end{array}$} & \multicolumn{4}{|c|}{ Control Group } & \multicolumn{4}{|c|}{ Study Group } \\
\hline & \multicolumn{2}{|c|}{ RE } & \multicolumn{2}{|c|}{ LE } & \multicolumn{2}{|c|}{ RE } & \multicolumn{2}{|c|}{ LE } \\
\hline & TB & Speech & TB & Speech & TB & Speech & TB & Speech \\
\hline \multicolumn{9}{|l|}{ P300 latency } \\
\hline Mean & 313.6 & 326.3 & 312.7 & 335.3 & 316.9 & 296.1 & 331.9 & 306.7 \\
\hline Median & 311 & 330 & 308 & 350 & 310 & 281 & 318 & 278 \\
\hline Standard Deviation & 25.8 & 39.8 & 22.2 & 34.3 & 43.3 & 50.4 & 36.2 & 51.8 \\
\hline P-value & \multicolumn{2}{|c|}{$p=0.312$} & \multicolumn{2}{|c|}{$p=0.066$} & \multicolumn{2}{|c|}{$p=0.398$} & \multicolumn{2}{|c|}{$p=0.314$} \\
\hline \multicolumn{9}{|l|}{ P3-N2 amplitude } \\
\hline Mean & 8.92 & 7.11 & 8.26 & 7.29 & 4.48 & 4.2 & 5.1 & 4.4 \\
\hline Median & 7.9 & 7.52 & 7.65 & 7.01 & 4.55 & 3.65 & 3.07 & 3.69 \\
\hline Standard Deviation & 3.57 & 3.36 & 3.43 & 3.27 & 2.71 & 2.96 & 4.03 & 2.57 \\
\hline P-value & \multicolumn{2}{|c|}{$p=0.110$} & \multicolumn{2}{|c|}{$p=0.515$} & \multicolumn{2}{|c|}{$p=0.767$} & \multicolumn{2}{|c|}{$p=0.953$} \\
\hline
\end{tabular}

Legend: $\mathrm{RE}=$ right ear; $\mathrm{LE}=$ left ear; $\mathrm{TB}-$ Tone-burst. ${ }^{*}$ Significant values $(\mathrm{p}<0.05)$. Statistical test: Mann-Whitney.

\section{DISCUSSION}

A stroke can affect the specific language-related areas of the brain, impairing the individual in their ability to communicate. Thus, a condition of aphasia is characterized, which can be present in one-third of the people who have had a stroke ${ }^{17,18}$. Accordingly, this study found stroke as the underlying disease in $90 \%$ of the individuals in the SG.

Considering the communication alterations and the possible cognitive alterations potentially caused by a stroke, this study analyzed the results of the functioning of both the peripheral and central auditory systems, highlighting that the hemisphere where the injury took place can interfere with the language affection in the aphasics.

In the TEOAE and suppression of the OAE, when comparing both ears, a statistically significant difference was observed between right and left ears in the OAE responses of the SG. Therefore, the ears differed in amplitude in the research both with and without noise (Table 1); greater amplitude was observed in the right ear in both conditions. These findings confirmed data from the literature, which described greater TEOAE amplitudes in the right ear, as well as in female individuals ${ }^{19,20}$. Hence, even with the neurological injury, the individuals of the SG had results similar to those observed in people without this alteration. As for the CG, no difference was observed between the ears in neither of the pick-up conditions.

Among the 10 aphasic individuals in the SG, four (40\%) did not present suppression of the OAE in at least one of the ears, in comparison with three individuals
(30\%) in the CG (Table 2). Therefore, it was noted that the medial efferent olivocochlear system (MOCS) was functional in most of the SG individuals (60\%) and the CG ones $(70 \%)$, there being no differences between the groups for the suppression of TEOAE test. Hence, the research on suppression effect was not sensitive to distinguish individuals with and without aphasia; however, the reduced number of participants may have contributed to the absence of significant differences. In the literature consulted, no research involving the suppression effect in the aphasic population was found.

The efferent portion of the auditory pathways, assessed through the suppression effect, is related to the understanding of speech in the presence of competing noise. It is known that acquired neurological disorders such as stroke can have consequences on the peripheral and central auditory pathways, justifying the absence of suppression observed in the SG. As for the absence of suppression in the CG, it could be related to alterations in the central auditory processing, even without a confirmed injury. In this sense, a study ${ }^{21}$ revealed that individuals with alteration in the central auditory processing who has impaired figure-ground and auditory closure skills can present alterations in the cochlear mechanism since in the presence of noise the inhibitory effect of the efferent pathway in the whole olivocochlear system is activated ${ }^{22}$.

When researching the cognitive potentials, mean $\mathrm{P} 3$ latency values of $318.1 \mathrm{~ms}$ for the right ear and $331.9 \mathrm{~ms}$ for the left ear were observed in the SG with the toneburst stimulus (Table 3). These values are lower than those from another study ${ }^{8}$, which presented a mean P3 
latency value of $369.7 \mathrm{~ms}$, and yet another ${ }^{9}$, with mean P3 latency value of $383.1 \mathrm{~ms}$. In this study, latency was higher for the left ear, which agrees with another study ${ }^{23}$, in which worse P3 latency and amplitude results were observed, always for the left ear, in aphasic individuals with left hemisphere injury caused by a stroke. Authors ${ }^{3}$ suggested that the absence or alteration in P300 response in aphasic individuals can be related to the linguistic alteration itself, with difficulties in the message decoding process.

Left temporal lobe injury also causes difficulties to understand speech, as well as alterations in speech production, evidenced by the alteration of the cognitive potential (P300) on the side of the injury ${ }^{24}$. Authors ${ }^{25}$ referred that the individual with aphasia and cortical injury on the frontal left area presented P3 latency delay and increased P3 amplitude values on the right side, which justifies the presence of injury on the left cortical and subcortical structures.

Nonetheless, another study ${ }^{26}$ involving right hemisphere injury resulting from an ischemic stroke showed a statistically significant tendency between right and left ears for the research group, with an increase in P300 latency wave for the right ear (the side of the injury), revealing an impairment of this potential's generating sites (subcortical and cortical areas) on the right hemisphere, which despite not being noticed by the person, could suggest a possible auditory hemineglect.

It is known that the recognition of verbal auditory stimuli depends on the left hemisphere and the nonverbal auditory stimuli are preferably processed by the right hemisphere in right-handed individuals ${ }^{27}$. Furthermore, it is known that the contralateral pathways are more predominant than the ipsilateral in the auditory afference. In this study, such differentiation was observed, as the decrease in the amplitude of P3 took place in the study group in both ears, with the lowest value $(4.2 \mu \mathrm{V})$ when the eliciting stimulus was speech to the right ear, and the highest value $(5.1 \mu \mathrm{V})$ when the stimulus was tone-burst to the left ear (Table 4). This corroborates a study ${ }^{28}$ that observed a mean P3 amplitude value of $8.6 \mu \mathrm{V}$ for the tone-burst stimulus, with greater amplitude to the left ear. Nevertheless, in this study higher mean values for TB stimulus were observed when compared with speech stimulus for both ears.

In this study (Table 4), when the potential was elicited with speech stimulus, lower latency and amplitude values were observed in the aphasic group in comparison with the control group; however, it is not justified that the individual with acquired neurological alteration present lower latencies than the control group since the cortical injury could lead to an increase in the time taken to process the information. It should be noted that the values observed for both groups are within normality standards, which expect great variation as the picked-up potential goes into the nervous system.

Concerning the amplitude, it can be inferred that fewer neurons were triggering synchronically to form the wave, which would be compatible with the central dysfunction resulting from the stroke.

The cognitive potential in individuals with acquired neurological alteration has already been investigated by many authors, as is the case of a study ${ }^{29}$ that evaluated the cognitive potential in individuals with mild traumatic brain injury and observed that $60 \%$ of the sample presented P3 latency within the expected.

A study ${ }^{30}$ observed P300 alteration in aphasic individuals, characterized by the absence of $\mathrm{P} 3$ and/or P3 wave latency delay, justifying that a brain injury can impair the cognitive processes, with a loss to attention, auditory discrimination and memory, and/or underlying language skills. This did not happen in this study, as the aphasic individuals did not present latency delay and there were no absent components. Nonetheless, it must be remembered that the normality standards for P3 are broad, between 225 and 427 ms for tone stimulus ${ }^{16}$, and that this component's generating sites are not yet clearly defined, possibly reflecting the contribution of multiple generators. Considering the plasticity of the nervous system, different structures not necessarily involved in the primary injury may have contributed to generate the wave when this potential was picked up.

Therefore, it is made clear that there is need for further studies involving the assessment of the functioning of the medial efferent olivocochlear system (MOCS), as well as the electrophysiologic auditory assessment, surveying the relationship of the peripheral and central auditory system with communication alterations and possible cognitive alterations in individuals with aphasia, separating them whenever possible according to the injury's topodiagnosis and with more robust samples. 


\section{CONCLUSION}

Based on this study's results, it is concluded that:

- there were no differences regarding the presence of otoacoustic emissions with and without noise in comparison with the groups with and without aphasia - i.e., the presence of suppression of the OAE was not different between the groups.

- in the cognitive potential with a tone-burst stimulus, the individuals with aphasia presented a decreased amplitude of P3 in their right ear, when compared with individuals with no aphasia.

- in the cognitive potential with speech stimulus, the individuals with aphasia presented a decreased amplitude of P3 in their left ear, when compared with individuals with no aphasia.

- individuals with and without aphasia presented latency of P3 within normality, both for the tone and the speech stimuli.

\section{REFERENCES}

1. Ortiz KZ. Afasia. In: Ortiz KZ (org). Distúrbios neurológicos adquiridos: linguagem e cognição. São Paulo: Manole; 2005. p. 47-64.

2. Mansur LL, Luiz MOR. Distúrbios da linguagem: afasias. In: Russo IP (org). Intervenção fonoaudiológica na terceira idade. Rio de Janeiro: Revinter; 1999. p.101-19.

3. Alvarenga KF, Lamônica DC, Filho OAC, Banhara MR, Oliveira DT, Campo MA. Electrophysiological study of the central and peripheral hearing system of aphasic individuals. Arq Neuropsiquiatr. 2005;63(1):104-9.

4. Ryan S, Kemp DT. The influence of evoking stimulus level on the neural suppression of transient evokedo to acustic emissions. Hear Res. 1996;94(1-2):140-7.

5. Hill JC, Prasher DK, Luxon LM. Evidence for efferent effects on auditory afferent activity, and their functional relevance. Clin Otolaryngol AlliedSci. 1997;22(5):394-402.

6. Silva TR, Dias FAM. Laterality of activity of medial olivocochlear efferent system: preliminar study. Rev. CEFAC. 2015;17(6):1855-62.

7. Onoue SS, Ortiz KZ, Minett TS, Borges AC. Audiological findings in aphasic patients after stroke. Einstein. 2014;12(4):433-9.

8. Grotto K. Achados do potencial evocado auditivo de longa latência e cognitivo (p300) em indivíduos afásicos [Monografia]. Porto Alegre (RS):
Universidade Federal do Rio Grande do Sul, Curso de Graduação em Fonoaudiologia; 2013.

9. Berticelli AZ, Grotto K, Rocha V, Brandão L, Sleifer P. Potenciais evocados auditivos de longa latência e potencial cognitivo em indivíduos afásicos. Estud. interdiscip. Envelhec. 2016;21(3):235-50.

10. Jerger JF. Clinical experience with impedance audiometry. Arch Otolaryngol. 1970;92(4):311-24.

11. Lloyd LL, Kaplan H. Audiometric interpretation: a manual o basic audiometry. University Park Press: Baltimore; 1978.

12. Hood LJ. Clinical applications of the auditory brainstem response. San Diego: Singular Publishing Group; 1998.

13. Souza LCA, Piza MRT, Alvarenga KF, Cóser PL. Eletrofisiologia da audição e emissões otoacústicas: princípios e aplicações clínicas. 2nd ed. Ribeirão Preto: Novo Conceito, 2010.

14. Nascimento BJ. Efeito de supressão das emissões otoacústicas em mulheres normo ouvintes [Monografia]. São Paulo (SP): Universidade Federal de São Paulo - UNIFESP, Curso de Graduação em Fonoaudiologia; 2014.

15. Jasper HH. The tentwenty electrode system of the international federation. Electroencephalogr Clin Neurophysiol. 1958;10:370-5.

16. McPherson D. Late potentials of the auditory system. San Diego: Singular Publishing Group; 1996.

17. Paolucci S, Matano A, Bragoni M, Coiro P, De Angelis D, Fusco FR et al. Rehabilitation of left brain-damaged $s$ chemic troke atients: he ole of comprehension anguage déficits. A matched comparison. Cerebrovasc Dis. 2005;20(5):400-6.

18. Townend E, Brady M, Mclaughlan KA. Systematic evaluation of the adaptation of depression diagnostic methods for stroke survivors who have aphasia. Stroke. 2007;38(11):3076-83.

19. Azevedo MF. Emissões otoacústicas. In: Figueiredo MS (org). Emissões otoacústicas e BERA. São José dos Campos: Pulso; 2003. p. 35-84.

20. Silva VG. Prevalência de alterações das células ciliadas externas em estudantes deuma escola do Distrito Federal [Monografia]. Brasília (DF): Universidade de Brasília, Faculdade de Medicina; 2012.

21. Burguetti FA, Carvallo RM. Efferent auditory system: its effecton auditory processing. Braz J Otorhinolaryngol. 2008;74(5):737-45. 
22. Brito NFS. Ativação do efeito inibitório da via eferente auditiva por estímulo de fala [Dissertação]. São Paulo (SP): Faculdade de Medicina, Universidade de São Paulo; 2015.

23. Zeigelboim BS, Klagenberg KF, Liberalesso PBa, Menezes P, Gonçalves DV. Neurophysiologic evaluation of auditory pathway sand the balance in Broca's aphasia - presentation of illustrative case. J. epilepsy clin. neurophysiol. 2010;16(4):143-8.

24. Matas CG, Leite RA, Mansur LL, Guilhoto LMFF, Manreza MLG. Long-term course of LandauKleffner syndrome: visuo-semantic and auditory aspects of comprehension. Rev Neurocienc. 2008;16(1):67-70.

25. Melo IHP, Vieira AC, Advíncula KP, Griz S, Cunha DA, Silva HJ. Potenciais evocados audotivos de longa latências: um estudo de caso de afasia de expressão. Rev. CEFAC. 2007;9(3):411-6.

26. Magliaro FCL, Matas SLA, Matas CG. Cognitive potential - P300 in patients with right hemisphere ischemic lesion. Pró-Fono R. Atual. Cient. 2009;21(4):285-90.

27. Luria AR. Higher cortical functions in man. 2 nd ed. New York: Basic Books; 1966.

28. Berticelli AZ, Sleifer $P$, Grotto $K$, Brandão L. Potenciais evocados auditivos e afasia crônica: marcadores de prognóstico para a reabilitação. 34a Semana Científica do Hospital de Clínicas de Porto Alegre. Clin Biomed Res. 2014;34 (Supl.):101.

29. Buriti AKL. Avaliação comportamental e eletrofisiológica do processamento auditivo central em indivíduos com traumatismo cranioencefálico leve, pré e pós-treinamento auditivo acusticamente controlado [Tese]. São Paulo (SP): Universidade Federal de São Paulo; 2019.

30. Folgearini JS, Biaggio LPV, Bruno RS, Oppitz SJ, Fedosse E, Santos SN et al. Processamento auditivo da informação em sujeitos com afasia. Estud. interdiscip. Envelhec. 2016; 21(3):217-34. 